\title{
A Experiência do Adoecer: uma Discussão sobre Saúde, Doença e Valores
}

\author{
The Experience of Falling Ill: a Discussion \\ about Health, Disease and Values
}

\author{
Debora Carvalho Ferreira \\ Irene Duarte Souza ${ }^{I I}$ \\ Cinthia Rafaela Santos Assis ${ }^{I I}$ \\ Mario Sergio Ribeiro ${ }^{I I}$
}

\section{PALAVRAS-CHAVE}

- Prática Profissional;

- Relações Médico-Paciente;

- Humanização da Assistência;

- Educação Médica.

\section{KEYWORDS}

- Professional Practice;

- Doctor-Patient Relations;

- Humanization of Care;

- Medical Education.
Recebido em: 11/01/2013

Reencaminhado em: 14/02/2014

Aprovado em: 17/04/201

\section{ABSTRACT}

Starting from a discussion of the concept of health and disease, it is clear that one of the current approaches includes the perception of the subject in relation to his/her condition. But the hegemony of the clinical method fails to consider such individuality, leading some professionals to discuss the changing needs of the medical approach. By discussing this case in question, it becomes clear that the doctor-patient relationship directly or indirectly influences the satisfaction and health of the patient, as well as the quality of the health services. Effective care requires a careful eye to the patient's real needs and respect for their opinions about the illness, their perceptions and culture. Person-Centered Medicine is a clinical method that proposes a medical approach that enables comprehensive, humanistic care and respect for the autonomy of individuals.
REVISTA BRASILEIRA DE EDUCAÇ̃̃O MÉDICA
${ }^{I}$ Universidade Federal de Viçosa, Viçosa, MG, Brasil.

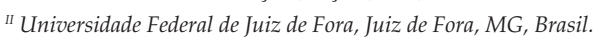




\section{INTRODUÇÃO}

O que é ter saúde? O que é estar doente? Tais indagações fazem parte não somente do cotidiano dos profissionais de saúde como também de todas as pessoas, principalmente quando se deparam com o diagnóstico de alguma doença. Estudiosos das áreas de sociologia, psicologia e antropologia médica cunharam o termo experiência da enfermidade para tentar abarcar estas considerações, discutindo a noção de saúde e doença como fenômenos complexos que conjugam fatores biológicos, sociológicos, econômicos, ambientais e culturais ${ }^{1}$.

A Organização Mundial da Saúde, em 1946, definiu saúde como "um completo estado de bem-estar físico, mental e social, e não apenas ausência de doença"(p.1)2. Tal definição tem sido discutida como utópica, principalmente pela dificuldade de se definir "um completo estado de bem-estar", uma completude inatingível pela própria condição humana ${ }^{3}$. Lunardi ${ }^{4}$ amplia esta crítica ao conceito de saúde, aprovado pela VIII Conferência Nacional de Saúde ${ }^{5}$, muito abrangente ao englobar fatores relativos à organização social como determinantes da saúde.

Dejours $^{6}$ destaca a saúde como um processo vivido pelas pessoas singularmente, em nível orgânico e psíquico. Tal enunciado é originário da perspectiva conceitual de Cangui$\mathrm{lhem}^{7}$, que, em sua obra $O$ Normal e o Patológico, discute a (i) legitimidade da norma no discurso médico para enquadrar as pessoas em diagnósticos definidos, nos quais a saúde e a doença teriam fronteiras rígidas:

\footnotetext{
Norma significa enquadro - aquilo que não se inclina nem para a esquerda nem para a direita, portanto, o que se conserva num justo meio-termo; daí derivam dois sentidos: é normal aquilo que é como deve ser; e é normal, no sentido mais usual da palavra, o que se encontra na maior parte dos casos de uma espécie ou o que constitui a média ou o módulo de uma característica mensurável (p. 48)
}

O exercício da clínica necessita de critérios objetivos - ou seja, padrões de verdade - para fundamentar sua prática, mas, já no século XIX, Nietzsche apontava a irracionalidade humana, demasiadamente humana, que se esconde por trás da vontade de verdade. Se a moderna epistemologia já afirmava a verdade como tarefa e a razão como construção, Nietzsche nos apresentou a verdade e a ciência como ficções sustentadas por uma mesma perspectiva de valores ${ }^{8}$.

É oportuno apreciar que a palavra valor provém de valere, do latim, que significa passar bem. Canguilhem ${ }^{7}$ realiza um raciocínio por antonímia com não valor, que significaria estar doente, ou seja, uma desvalorização, uma perda do próprio valor. Em oposição ao bem-estar, o estar doente seria nocivo, social e individualmente desvalorizado e indesejável.

Camargo-Júnior ${ }^{9}$ afirma que a relação entre o saber e a prática médica nem sempre é harmoniosa, devido à inadequação deste conhecimento à realidade. As rotinas diagnósticas tornam-se marcadas pela mecanização na caracterização de doenças, a terapêutica pelo método do "ensaio e erro" e prescrição de sintomáticos - por vezes mal empregados quando afiançados pelo bulário e incentivados pelas propagandas da indústria farmacêutica.

Críticas a esta prática não harmoniosa já estão, há muito, presentes na literatura Podemos citar, entre outros, na literatura internacional, Ballint ${ }^{10}$ e Illich $^{11}$, e, no Brasil, Caprara e Franco $^{12}$, Camargo-Júnior ${ }^{9}$, Caprara e Rodrigues ${ }^{13}$, assim como Norman e Tesser ${ }^{14}$, os quais nomeiam esta prática como má medicina, caracterizando-a como arrogante, autoritária, beligerante e controladora, com uma visão imaginária do médico enquanto um herói solitário, que carrega o peso de missão impossível.

Em meio a essa missão impossível, o profissional apoia-se num arsenal tecnológico que coloca à sua disposição várias opções para lidar com cada fragmento do homem, mas pode faltar-lhe a habilidade para lidar com o paciente em sua unicidade. $\mathrm{O}$ processo de racionalização da medicina moderna baseia-se em abordagens objetivas e quantificáveis, subestimando a dimensão psicossociocultural dos sujeitos. Os profissionais de saúde e seus pacientes pertencem à mesma cultura, mas ambos interpretam o processo saúde-doença de formas diferentes.

Para Caprara e Rodrigues ${ }^{13}$, a relação médico-paciente pode ser definida como uma relação assimétrica. Esta assimetria levaria a desencontros no que tange ao sofrimento do paciente, causador da busca pelo cuidado. Machado e Lavrador ${ }^{15}$ trazem uma discussão sobre as múltiplas facetas da vivência do sofrimento e como ela pode influenciar os arranjos desta relação entre o profissional e a pessoa que busca cuidado; isto é: a relação pode variar de passiva e expectante àquela que exige uma negociação compartilhada que caminha para a autonomia daquele que sofre.

Em parte, a história da medicina caminhou no sentido da priorização das doenças e seu processo diagnóstico em detrimento da pessoa que sofre o padecimento ${ }^{16,17}$. Esta priorização ocorreu em paralelo à busca de uma ordem, uma norma, para fundamentar diagnósticos e terapêuticas apropriados. Os padrões sintomáticos que se repetiam em determinados padecimentos foram nomeados doenças, independentemente da variância individual do processo do adoecer. A doença passou a ser considerada um desvio do que se espera do or- 
ganismo normal, uma perturbação passível de ser diagnosticada e tratada.

Historicamente, a hegemonia deste método clínico não atento à subjetividade - construção de diagnósticos por meio da articulação de sinais e sintomas definidores de uma doença descrita nos compêndios médicos - foi seguida da emergência de críticas e insatisfações, em especial quanto à real eficácia em satisfazer as necessidades de saúde das pessoas, assim como em promover a satisfação dos próprios médicos com seu ofício $^{10}$. Particularmente no início da década de 1980, alguns médicos condensaram essas insatisfações em discussões acerca da necessidade de mudança na abordagem médica. Um dos desdobramentos destas discussões foi a conformação de uma abordagem denominada "Medicina Centrada na Pessoa"10,18,19.

A Medicina Centrada na Pessoa é definida como um método clínico que, por meio de uma escuta atenta e qualificada, objetiva um entendimento integral da vivência individual daquele padecimento, a fim de construir conjuntamente um plano terapêutico, estimulando a autonomia da pessoa no processo ${ }^{18}$.

O presente artigo apresenta um caso clínico fictício (adaptado de uma situação real vivenciada por um dos autores durante a residência médica) para fundamentar uma discussão acerca do embate de valores entre profissionais de saúde e pacientes no cotidiano de suas relações, relativamente às distintas percepções de conceitos e normas de saúde e doença. Objetivamos, com esta discussão, trazer para o nível das individualidades envolvidas a vivência do processo saúde-adoecimento e seus desdobramentos.

\section{RELATO DO CASO}

O relato a seguir é baseado em um enredo adaptado de uma situação real de atendimento, realizado em um ambulatório de clínica geral de uma residência de medicina de família e comunidade. A personagem deste caso será Joaquim: 80 anos; branco; natural de Portugal; católico; casado há 53 anos; residente em um grande centro urbano com a esposa e a filha mais nova; comerciante autônomo aposentado, que mantém atividade profissional.

O sr. Joaquim iniciou sintomas de tonteiras nos dias antecedentes à consulta e chegou a apresentar um episódio de desmaio. Juntamente a tais sintomas, começou a queixar-se de "fraqueza nas pernas e sensação de falta de ar". Estes sintomas pioram quando faz atividade física, como caminhada. Paciente e família negam episódios semelhantes no passado. A filha relata que o levou para consulta particular com otorrinolaringologista há três dias. Após breve consulta e exame do ouvido, foi-lhe prescrita medicação para labirintite, que não resultou em melhora.
Na consulta atual, o sr. Joaquim mostrou a medicação em uso e informou história de hipertensão arterial, gota, úlcera péptica e varizes de membros inferiores. Durante o exame clínico, foi identificada uma alteração do ritmo cardíaco, capaz de justificar a sintomatologia em questão. Realizado o eletrocardiograma, foi diagnosticada uma arritmia cardíaca com indicação de internação hospitalar para tratamento. O sr. Joaquim permaneceu internado por 15 dias, em hospital universitário, para realizar exames complementares e tratamento adequado; recebeu alta com melhora relativa, pois a tonteira ainda era presente. Após 15 dias da alta hospitalar, retornou ao hospital alegando piora das tonteiras e "sensação de coração acelerado e inchaço no rosto e no corpo". Foi internado na Unidade de Terapia Intensiva, uma vez identificada a gravidade do quadro: provável efeito adverso do antiarrítmico em uso. Após melhora, voltou para a enfermaria, e vários procedimentos foram avaliados na tentativa de normalizar seu ritmo cardíaco.

Teve alta após quase dois meses, sem resolução completa do quadro de arritmia cardíaca e dos sintomas envolvidos. A equipe médica assistente indicou que, além do uso dos fármacos, o sr. Joaquim teria que aprender a conviver com suas limitações físicas, que implicariam restrições quanto ao trabalho. A família, sempre muito cuidadosa, preocupou-se em obedecer a todas as recomendações médicas. Entretanto, o sr. Joaquim, que sempre foi uma pessoa ativa, começou a manifestar mudanças de humor e de atitudes. Estava muito incomodado com todas as restrições, com o fato de não poder mais trabalhar e de ficar limitado ao domicílio, o que, em 80 anos de vida, nunca havia acontecido.

A família se tornou muito apreensiva com estas mudanças de humor, e a médica de família foi chamada para uma consulta domiciliar. Nela, a médica pôde observar a mudança de postura do sr. Joaquim, que se mostrava recolhido, calado, intimidado e tendendo ao choro fácil. Com uma abordagem médica, considerando a subjetividade do paciente, a médica pôde concluir que o sr. Joaquim estaria vivendo uma situação de desajustamento à sua nova realidade. Não à realidade da doença cardíaca, mas, sim, à impossibilidade de se manter em seu ritmo de vida anterior, quando tinha autonomia e se sentia um homem produtivo. Para ele, esta circunstância era uma questão de valores, que lhe foram retirados abruptamente.

Abordando-se o problema por esta perspectiva, que envolveu a participação ativa de toda a família (incluídos os três outros filhos, que já não residem na mesma casa), todos concordaram em que a prática do "não pode" - recomendação anterior - não estava dando certo. Após tal constatação, um acordo familiar foi feito, e todos concordaram em dividir entre si a responsabilidade de proporcionar ao sr. Joaquim uma 
forma de retorno ao seu trabalho, sempre com alguém o acompanhando. Pouco a pouco, o sr. Joaquim foi retomando seu humor habitual, e, mesmo com o coração fora do ritmo, sua vida pôde voltar ao ritmo normal.

\section{DISCUSSÃO}

O caso acima foi utilizado para trazer a realidade cotidiana à discussão proposta acerca de normas e valores, sem colocar em foco a abordagem biomédica das arritmias.

Canguilhem ${ }^{7}$ aponta que a fronteira entre o normal e o patológico - sadios e doentes - frequentemente se dá por uma comparação com uma norma resultante da média esperada para uma população específica. Ainda que consideradas as exigências e o rigor do método científico, o autor afirma que uma média, obtida estatisticamente, não permite afirmar que determinado indivíduo é normal ou não. Existencialmente, o relevante não é a norma estatística, mas os desdobramentos e desencontros impostos à vida da pessoa e as consequências biopsicossociais que as intervenções focadas estritamente na dimensão biológica podem gerar.

O conhecimento dos profissionais de saúde estabelece claramente a fronteira entre o normal e o patológico, traduzida em um padrão que fundamenta diagnósticos e intervenções. Em relação à percepção do indivíduo, não existe uma rigidez determinística para todas as pessoas. Há uma flexibilidade em relação às condições individuais, e a fronteira entre o normal e o patológico pode ser perfeitamente precisa se considerada para um único indivíduo. Portanto, estar doente passa a ser uma norma individual?

Desta forma, o indivíduo é quem avalia a transformação do normal em patológico, porque é ele quem sofre as consequências no momento em que se sente incapaz de realizar as tarefas que a nova situação lhe impõe $\mathrm{e}^{7}$. É a partir do julgamento individual de estar doente que cada pessoa sente a necessidade de procurar assistência:

São os doentes que geralmente julgam - de pontos de vista muito variados - se são normais ou voltaram a sê-lo. Para um homem que imagina seu futuro quase sempre a partir de sua experiência passada, voltar a ser normal significa retomar uma atividade interrompida, ou pelo menos uma atividade considerada equivalente, segundo os gostos individuais ou valores sociais do meio. Mesmo que essa atividade seja uma atividade reduzida, mesmo que os comportamentos possíveis sejam menos variáveis, menos flexiveis do que eram antes, o indivíduo não dá importância assim a estes detalhes. O essencial, para ele, é sair do abismo de impotência ou de sofrimento em que quase ficou definidamente. (p. 91)
O sofrimento é que desencadeia a busca de assistência e, para a pessoa, é algo palpável, que pode incapacitá-lo. Por outro lado, para o profissional de saúde, o sofrimento do sujeito pode tornar-se irrelevante, já que, imbuído de seu papel de detetive das doenças, deve inclinar-se à procura do distúrbio de maneira objetiva9 . Em especial, quando a relação do profissional é com a doença, considerada a realidade concreta de sua intervenção, o paciente seria apenas o seu meio de acesso à doença. Segundo Camargo-Júnior ${ }^{9}$, a referência à doença é um "artifício criado para enquadrar os fenômenos do processo saúde-doença" (p. 78). O perigo está na valorização do artifício em detrimento do sofrimento do paciente.

Algumas vezes, os profissionais de saúde atuam como se as doenças fossem algo monolítico, sem contato com as perspectivas culturais ou individuais. Nesta configuração, o profissional torna-se menos atento aos temores, às preocupações e às necessidades dos pacientes, não os valorizando nem amparando os pacientes. O que o paciente percebe como doença pode ser distinto do entendimento do médico, e este conflito pode influenciar negativamente as ações propostas pelo médico e as reações do paciente ${ }^{9}$.

Laplantine $^{20}$ referencia o saber médico, no imaginário popular, como um instrumento de certeza e poder de coerção. A reação é a introjeção de dois movimentos possíveis pelos pacientes: obediência ou transgressão às leis impostas pelo profissional. Estas condutas, que perpassam do imaginário ao real, podem gerar sentimentos de culpa, condenação ou justiça. Isso seria um salvo-conduto pela obediência, que significa uma boa saúde. Consequentemente, uma prática de negociação compartilhada e que considere a subjetividade do paciente é muito importante para reverter assimetrias na relação médico-paciente e suas consequências.

Para determinar suas normas, a medicina busca fundamentar-se em evidências, que costumam ser tomadas como verdades atemporais, determinadas pela ciência. Mattos ${ }^{21}$ considera a intervenção médica cientificamente fundamentada como a mais confiável. Contudo, o autor assegura que nada garante que o cientificamente fundado seja o melhor. Ele questiona se seria cabível a defesa da destruição do planeta ou da humanidade, ainda que decorrente de ações cientificamente fundadas. A rigor, decisões não são tomadas exclusivamente com base no conhecimento científico, mas também alicerçadas nos valores que defendemos.

O caso relatado ilustra o embate entre os valores normatizantes da ciência e os valores das pessoas envolvidas. Na tradição do pensamento moderno, a ciência se constrói contra o senso comum, rompendo com uma série de crenças e valores ${ }^{22}$. Pretende-se buscar uma forma superior de conhecimento, me- 
nos permeada por paixões e opiniões, que, todavia, não é menos independente dos valores.

Canguilhem $^{7}$ discute se a tendência fundamental do ser vivo seria a conservação ou a expansão da vida. É observada, na preocupação mórbida em evitar situações eventualmente geradoras de reações catastróficas, a expressão do instinto de conservação ${ }^{7}$. No caso do sr. Joaquim, a preocupação dos profissionais com a possibilidade de morte devido a uma queda (situação geradora de reação catastrófica) pode ser tomada como expressão desse instinto de conservação, desdobrado nas limitações impostas ao paciente. Mas este instinto não seria a lei geral da vida, e sim a lei de uma vida limitada ${ }^{23}$.

Para Boaventura Santos apud Mattos"21 " "a ciência moderna tem sido mais capaz de desencadear ações (ou intervenções) do que antecipar as possíveis consequências dessas mesmas ações (ou intervenções)" (p.119). Desta maneira, não devemos prescindir da cientificidade e das benesses geradas pelo modelo científico da medicina, mas tem que se reconhecer a inexistência de um modelo ideal, que seria normativo e resolutivo em todas as situações e em todos os indivíduos. Há de se considerar as subjetividades e não desqualificar e silenciar os valores e conhecimentos de outras genealogias. O conhecimento médico, científico, pautado pela prudência, pela responsabilidade e também pelo compromisso ético, consequente e compartilhado de forma simétrica, poderá responder melhor às questões do caso relatado.

É nesta perspectiva que se insere a Medicina Centrada na Pessoa, como um método clínico que propõe uma humanização das ações dos profissionais. Constitui uma proposta para uma prática que não admite a doença como foco da intervenção do profissional e traz o sujeito e suas necessidades individuais ao primeiro plano da relação terapêutica. A Medicina Centrada na Pessoa busca uma assistência contínua e compreensiva, que fortaleça uma relação simétrica entre o binômio profissional-paciente, na qual os pacientes têm um papel autônomo e protagonista em seu processo de saúde-doença ${ }^{24}$.

Uma das limitações desta proposta é que ela depende fortemente das habilidades comunicativas tanto do paciente quanto do médico ${ }^{18}$. O mais significante nesta abordagem é que o ponto de partida é sempre a pessoa, e não o corpo ou a doença ${ }^{8}$. Este movimento pode ser uma ponte entre o mundo médico científico e o mundo das pessoas que procuram seus cuidados ${ }^{25}$. Finalmente, poderia resultar em menor frequência de conflitos de valores entre profissionais de saúde e pacientes, além de um manejo mais sinérgico do cuidado.

\section{CONCLUSÕES}

Neste texto, buscamos partir de um amplo conceito de saúde-doença para uma discussão de como isto se dá na prática moderna dos profissionais de saúde. Percebemos, por meio da discussão do caso relatado, que a relação médico-paciente influencia direta ou indiretamente a satisfação, o estado de saúde do paciente e, por conseguinte, a qualidade dos serviços. O profissional deve a ter sensibilidade de ouvir o paciente, conhecer sua realidade e, assim, chegar a um ponto comum sobre as ações mais eficazes na mudança do "modo de vida", observando além da doença ${ }^{8}$.

$\mathrm{O}$ "estar doente" depende da percepção do sujeito em relação à sua condição. Sendo assim, encarar este momento de sofrimento pode, finalmente, ser positivo ou se tornar uma situação com consequências negativas, dependendo da cultura do médico e da maneira de encarar a vida do paciente ${ }^{26}$.

Considera-se a não existência de um modelo ideal ou perfeito, que seja resolutivo em todas as situações e em todos os pacientes, tal como se afirma a inexistência de uma postura profissional generalizada atualmente. Intenta-se causar uma reflexão sobre a prática e sobre os métodos clínicos que valorizam a escuta, a negociação compartilhada e a subjetividade dos indivíduos, e que também impactem a humanização das intervenções dos profissionais. Desta maneira, se conformariam relações menos assimétricas entre médico e paciente.

Promover saúde não é tarefa simples e requer dos envolvidos no processo um olhar atento às reais necessidades do paciente e o respeito às opiniões sobre o adoecimento, suas percepções e sua cultura. $\mathrm{O}$ atendimento com uma equipe multidisciplinar e o trabalho interdisciplinar possibilitam a ação de diversas áreas do conhecimento e diferentes visões frente à mesma situação, fato que permitirá uma integração destes saberes, aliados aos conceitos e valores do paciente e, assim, uma atenção mais eficaz ao paciente ${ }^{26}$.

Nessa perspectiva, apresentou-se a Medicina Centrada na Pessoa como um dos métodos clínicos de abordagem integral e humanística, que mantém a resolubilidade das ações dos profissionais, respeitando a autonomia das pessoas.

\section{REFERÊNCIAS}

1. Alves PC. A experiência da enfermidade: considerações teóricas. Cad. saúde pública 1993;9(3):263-71.

2. World Health Organization. Constitution of the World Health Organization. Basic Documents [on line]. 45 $5^{\mathrm{a}}$ edition. Genebra: 2006. [capturado 12 fev. 2012]. Disponível em: http:/ /www.who.int/governance/eb/who_constitution_en.pdf. 
3. Segre M, Ferraz FC. O conceito de saúde. Rev. Saúde Pública 1997;31(5):538-42

4. Lunardi VL. Problematizando conceito de saúde a partir do tema da governabilidade dos sujeitos. Rev. gaúch. Enferm 1999;20(1):26-40.

5. Brasil. Conselho Nacional de Saúde. VIII Conferência Nacional de Saúde: relatório final [on line]. Brasília: 1986 [capturado 20 jan. 2012]. Disponível em: http://conselho. saude.gov.br/biblioteca/Relatorios/relatorio_8.pdf.

6. Dejours C. Por um novo conceito de saúde. Rev. bras. Saúde ocup 1986;14:7-11.

7. Canguilhem G. O normal e o patológico. Rio de Janeiro: Forense Universitária; 1990.

8. Ribeiro MS. Medicina, ciência e ética: filosofar é preciso? Rev. bras. educ. méd 2004;28(2):156-63.

9. Camargo-Júnior KR. Biomedicina, saber e ciência: uma abordagem crítica. São Paulo: Hucitec; 2003.

10. Ballint M. O médico, seu paciente e a doença. Rio de Janeiro: Atheneu; 1998.

11. Ilich I. A expropriação da saúde: nêmesis da medicina. Rio de Janeiro: Nova Fronteira; 1975.

12. Caprara A, Franco ALS. A relação paciente-médico: para uma humanização da pratica médica. Cad. saúde pública 1999;15(3):647-54

13. Caprara A, Rodrigues J. A relação assimétrico médico-paciente: repensando o vínculo terapêutico. Ciênc. saúde coletiva 2004;9(1):139-46.

14. Noman AH, Tesser CD. Prevenção quaternária na atenção primária a saúde:uma necessidade do sistema único de saúde. Cad. saúde pública 2009;25(9):2012-20.

15. Machado LD, Lavrador MCC. Por uma clínica de expansão da vida. Interface comun. saúde educ 2009;13(supl.1):51521.

16. Crookshank FG. The teory of diagnosis. Br Med J. 1926;2(3437): 955-956.

17. McWhinney IR. Método Clinico. In: McWhinney IR, Freeman T. Manual de Medicina de Família e Comunidade. 3.ed. Porto Alegre: Artmed; 2010. p 151-204.

18. Stewart M, Brown JB, Weston WW, McWhinney IR, McWilliam CL, Freeman TR. Medicina Centrada na Pessoa. 2 ed. Porto Alegre: Artmed; 2010.
19. Levenstein JH, McCracken EC, McWhinney IR, Stewart MA, Brown JB. The patient-centred clinical method. 1. A model for the doctor-patient interaction in family medicine. Fam Pract. 1986;3(1):24-30.

20. Laplantine F. Antropologia da doença. 4.ed. São Paulo: Martins Fontes; 2010.

21. Mattos R. Cuidado prudente para uma vida descente. In: Pinheiro R, Mattos R. Cuidado: as fronteiras da integralidade. Rio de Janeiro: CESPESC/UERJ, ABRASCO; 2005. p 119-132.

22. Bachelard G. A formação do espírito científico, contribuição para uma psicanálise do conhecimento. Rio de Janeiro: Contraponto; 1996.

23. Ribeiro MMF, Amaral CFS. Medicina centrada no paciente e ensino médico: a importância do cuidado com a pessoa e o poder médico. Rev. bras. educ. méd 2008;32(1):90-7.

24. World Health Organization. World health report 2008: primary health care now more than ever. Genebra: WHO; 2008.

25. Bensing J. Bridging the gap. The separate worlds of evidence-based medicine and patient-centered medicine. Patient Educ Couns. 2000;39(1):17-25.

26. Silva JLL. O processo saúde-doença e a importância para a promoção da saúde. Informe-se em promoção da saúde 2006; 2:3-5.

\section{CONTRIBUIÇÃO DOS AUTORES}

Todos os autores trabalharam em todas as fases do artigo.

\section{CONFLITO DE INTERESSES}

Os autores declaram não haver conflito de interesses de qualquer natureza nesta produção.

\section{ENDEREÇO PARA CORRESPONDÊNCIA}

Irene Duarte Souza

Rua Rafael Zacarias, 140 Democrata

Juiz de Fora- Minas Gerais

CEP 326035-290

E-mail: ireneduartesouza@gmail.com 